\title{
Türkiye'deki Ticari Bankalara Ait Web Sitelerin Performanslarının SWARA ve ARAS Yöntemi İle Siralanmasi
}

\author{
DOI: 10.26466/opus.888184 \\ * \\ Muhammed Maruf * - Kadir Özdemir ** \\ * Dr. Öğr. Üyesi, Kırşehir Ahi Evran Üniversitesi, İ̈BF, Kırşehir/Türkiye \\ E-Posta: m.maruf@ahievran.edu.tr \\ ORCID: 0000-0002-5388-639X \\ ** Arş.Gör., Şırnak Üniversitesi, İ̈BF, Şırnak/Türkiye \\ E-Posta: kadirozdemir@sirnak.edu.tr \\ ORCID: $\quad \underline{0000-0002-2034-4797}$
}

Öz

Günümüzde teknolojik gelişmeler ile birlikte küresel olarak birçok alanda önemli dönüşümler başlamış olup ekonomik ve ticari faaliyetlerin birçoğu internet ortamına taşımıștır. Böylece birçok sektörde dijitalleşmeye geçişi hızlanmıştır. Özellikle bankacılık sektörü dijital dönüşüme en hızlı adapte olan sektörlerden biridir. Bankacllık sektöründeki dijital dönüşümün hızlanmasıyla birçok banka şubelerinde sunduğu hizmetleri web sitelerinde internet bankaciliğı uygulamaları aracilı̆̆ıla da sunmaya başlamıştır. Böylece bankalara ait web sitelerin önemi artmıştır. Bu bağlamda bu çalışmada Türkiye'deki 15 ticari bankanın web sitelerinin performansin amaçlanmıştır. Web sitelerinin performans kriterlerine göre siralanmasında SWARA ve ARAS yöntemleri kullanılmıştır. SWARA yöntemi sonuçlarına göre banka web sitesi performansinın değerlendirilmesinde sayfa açılma süresi ve hız endeksi kriterleri en yükse ağırlı̆̆a sahip kriterler olarak bulunmuşken, web sitesinde geçirilen ortalama süre, dünya sıralaması ve Türkiye stralaması kriterleri ise en düşük ağırlğ̆l sahip kriterler olarak bulunmuştur. ARAS yöntemi sonucunda hesaplanan fayda değerlerine göre ise sirasıyla HSBC, Fiba Bank ve Şeker Bank'ın en iyi performans gösteren web sitelerine sahip olduğu sonucuna ulaşılmıştır. Türkiye Ekonomi Bankası, ING Bank ve Akbank ise en kötü performans gösteren web sitelerine sahip olup yapılan sıralamada son üç sırada yer almıştır.

Anahtar Kelimeler: SWARA, ARAS, Web sitesi, Bankacılı. 
ISSN:2528-9527

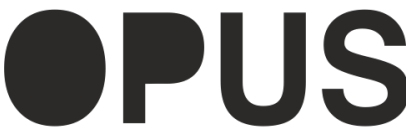

Uluslararası Toplum Araştırmaları Dergisi International Journal of Society Researches
E-ISSN: 2528-9535

Yıl Year. 11

Cilt Volume: 18

Sayı Issue: Yönetim ve Organizasyon Özel Sayısı

Temmuz July 2021

Makalenin Geliş Tarihi Received Date: 28/02/2021

Makalenin Kabul Tarihi Accepted Date: 01/05/2021

\title{
Ranking of Web Sites Performance of Commercial Banks in Turkey by SWARA and ARAS Method
}

$*$

\begin{abstract}
Nowadays, with the technological advancements, lots of significant transformations have started in many areas and many of the economic and commercial activities have been transferred to the online environment. Thus, transition to digitalization has accelerated in many sectors. Banking sector is one of the fastest sector which adapt to digital transformation. With the acceleration of digital transformation in the banking sector, many banks have commenced to offer lots of services through internet banking applicates on their websites. Thus, the importance of banking websites has increased. In this context, the main object of this study to analysis and rank of 15 commercial banks' websites according to website performance criteria. SWARA and ARAS methods were used to rank the websites. According to results of SWARA method page opening time and speed index were found to be the highest weighted criteria, while the average time spent on the websites, world ranking and Turkey ranking were found to be the lowest weighted criteria in the evaluation of the bank's website performance. On the other hand, according to the benefit values which calculated as a result of the ARAS method, it was concluded that HSBC, Fiba Bank, and Şeker Bank had the best performing websites. Also, TEB, ING Bank, and Akbank had the worst performing websites.
\end{abstract}

Keywords: SWARA, ARAS, Website, Banking 


\section{Giriş}

Teknolojinin gelişmesiyle dünya genelinde internet kullanımı her geçen gün artış göstermektedir (Thompson vd., 2019, s.239). Bu nedenle birçok sektörde dijitalleşmenin stratejik önemi artmış olup dijital dönüşüm hızlanmıştır. Bu bağlamda bankacilık sektörünün diğer sektörlere göre dijital dönüşüme daha hazırlıklı olduğu söylenebilir (Beybur ve Çetinkaya, 2020, s.148).

Bankacılık sektöründeki dijital dönüşümle birlikte birçok banka fiziksel olarak şubelerinde sunduğu hizmetleri web sitelerinde de sunmaya başlamıştır. Böylece bankalara ait web sitelerin önemi artmıştır ve bankalar için web siteleri iş süreçlerinin ayrılmaz bir parçası haline gelmiştir. Özellikle internet bankacılığının kullanımının ve öneminin arttı̆̆1 günümüzde bankaların misyon ve vizyonlarına ulaşmaları ve rekabet avantaji elde etmeleri için web siteleri önem arz etmektedir (Özdemir ve Turna, 2020, s.39).

Literatürde bankalara ait web siteleri ile ilgili çalışmalar incelendiğinde ise genel eğilimin web sitelerinin içerik analizi ve ele alınan bazı kriterlerin web sitesi kullanımı ile müşteri memnuniyetine etkisini anlamaya yönelik olduğu görülmektedir. Belirli kriterler ile bankaların web sitesi performansını inceleyen çok fazla çalışma bulunmamaktadır. Literatür araştırması sonucunda bu çalışmanın konusuyla paralellik gösteren bazı çalışmalar şunlardır; Ecer (2014), Türkiye'deki 17 bankanın web sitesi kalitesini AHP ve COPRAS-G yöntemlerini kullanarak değerlendirmiştir. Çalışmada bilgi kalitesi, servis kalitesi, anlaşılabilirlik, güncellik, ulaşılabilirlik, sistem kalitesi ve güvenilirlik gibi kriterler kullanılmıştır. Akgül (2018), Türkiye'de bulunan 32 bankanın web sitesini erişilebilirlik, kullanılabilirlik ve güvenlik kriterleri doğrultusunda analiz etmiştir. Çalışmada ayrıca web sitesi performansı, web sitesinin açılma süresi ve sayfa boyutu gibi kriterler de kullanılmıştır. Chmielarz ve Zborowski (2018), Polonya'daki 21 bankanın web sitesi performansını COMET yöntemini kullanarak değerlendirmiştir. Sarkar ve Pal (2018), Hindistan'daki 41 bankanın performansını toplam sayfa sayısı, toplam link sayısı ve web etki faktörüne (WIF) göre analiz etmiştir. Chmielarz ve Zborowski (2018), Polonya'daki 21 bankanın web sitesi kalitesini ve performansını TOPSIS 
yöntemi kullanarak değerlendirmiştir. Oyefolahan vd. (2019), Nijerya'daki 10 bankanın web sitesi performansını kullanılabilirlik ve erişilebilirlik kriterleri bağlamında analiz etmiştir. Özdemir ve Turna (2020), Türkiye'deki 10 ticari bankanın web sitesi performansını AHP, TOPSIS ve VIKOR yöntemlerini kullanarak analiz etmiştir. Çalışmada literatür ve uzman görüşüne dayanarak sayfa hızı, hız endeksi, biçimlendirme, ziyaretçi sayısı, sayfa açılma süresi ve sayfa görünümleri kriterleri kullanılmıştır.

$\mathrm{Bu}$ çalışma Türkiye'deki 15 ticari bankaya ait web sitelerinin performansını analiz ederek banka web sitlerini sıralamayı amaçlamaktadır. Bankalara ait web sitelerinin sıralanmasında kullanılan sıralama kriterleri literatürdeki çalışmalara dayanarak belirlenmiştir. Bu doğrultuda web sitesi performansı (\%), web sitesinin hızı endeksi (saniye), web sitesinin tamamen açlma süresi (saniye) ve web sitesi sayfa boyutu $(\mathrm{mb})$, ziyaretçilerin web sitesinden hemen ayrılma oranı (\%), toplam ziyaretçi sayısı, web sitenin dünya sıralaması, web sitesinin Türkiye sıralaması, web sitesinde geçirilen ortalama süre (dakika) ve ziyaret başına görüntülenen ortalama sayfa sayısı kriterleri kullanılarak web siteleri çok kriterli karar verme yöntemlerinden olan SWARA ve ARAS yöntemleri ile değerlendirilerek sıralanmıştır.

Çok kriterleri karar verme yöntemleri karar alternatiflerinin çok sayıda ve birbiri ile çelişen kriterlere göre sıralanması amaçlı olarak kullanılmaktadır. Literatürde karar kriterlerinin ağırlıklandırılması ve alternatiflerin sıralanması amaçlı olarak uygulanan çok sayıda çok kriterli karar yöntemi mevcuttur. En önemli ve en çok kullanılan kriter ağırlıklandırma yöntemlerinden biri olan ve birçok farklı problemin çözümünde kullanılan yöntemlerden birisi SWARA (Step-Wise Weight Assessment Ratio Analysis) yöntemidir. SWARA yönteminde karar verici olarak belirlenen uzmanların görüş ve fikirleri esas alınmaktadır. Bu nedenle bu yöntemde karar vericiler ekonomik ve çevresel koşullar bağlamında kendi önceliklerini belirleyebilmekte ve böylece diğer yöntemlere nazaran daha etkin bir rol oynayabilmektedir (Zolfani ve Saparauskas, 2013, s.140; Dahooie vd., 2018, s.10-11). Literatürde son yıllarda en yaygın kullanılan alternatif sıralama yöntemlerinden birisi ise ARAS (Additive Ratio Assessment) yöntemidir. ARAS yönteminde, belirlenen alternatiflerin fayda fonksiyonu değerleri dikkate alınmakta 
ve alternatifler fayda değerine göre siralanmaktadır. Ayrıca ARAS yönteminde alternatiflerin performans değerlerinin optimum fayda sağlayan alternatife göre oransal olarak benzerlikleri belirlenmektedir (Pelitli vd., 2018; Shariati vd., 2014, s.411; Ercan ve Kundakc1, 2017, s.90).

Literatür incelendiğinde SWARA ve ARAS yöntemlerinin farklı alanlardaki birçok çalışmada kullanıldığ 1 görülmektedir. SWARA ve ARAS yöntemlerinin ayrı ayrı kullanıldığı çok sayıda çalışma olmasına rağmen bu çalışmada bir arada kullanıldıkları için literatür araştırması da bu doğrultuda yapılmıştır. Bu bağlamda SWARA ve ARAS yöntemlerinin kullanıldığı çalışmalar incelendiğinde hibrit olarak personel seçiminde (Kersuliene ve Turskis, 2011; Karabasevic vd., 2015; Stanujkic vd., 2015; Karabasevic vd., 2016; Dahooie vd., 2018), elektrik forkliftinin seçiminde (Vockic vd., 2018), finansal performans değerlendirilmesinde (Gümüş vd., 2019), tedarik zinciri performansının değerlendirilmesinde (Korucuk, 2019), bina bakım strateji seçiminde (Ighravwe ve Oke, 2019), iç güvenlik denetçisi seçiminde (Prasad, 2019), motor çalışma performansının değerlendirilmesinde (Balki vd., 2020), enerji depolama teknolojilerinin performansının değerlendirilmesinde (Albawab vd., 2020), kuruluş yeri seçiminde (Mostafaeipour vd., 2020a; Mostafaeipour vd., 2020b) ve risk unsurlarının belirlenmesinde (Dehshiri ve Aghaei, 2020) kullanılan çalışmaların olduğu görülmüştür.

\section{Yöntem}

\section{SWARA Yöntemi}

Çok kriterli karar verme yöntemlerinden biri olan ve son zamanlarda birçok farklı problemin çözümünde sıkça kullanılan SWARA (Step-Wise Weight Assessment Ratio Analysis) yöntemi ilk defa Kersuliene vd. (2010) tarafından kullanılmıştır. Türkçe 'ye "Adım adım ağırlık değerlendirme oran analizi" şeklinde çevrilen SWARA en önemli ve en çok kullanılan kriter ağırlıklandırma yöntemlerinden biridir (Yurdoğlu ve Kundakcı, 2017: s.258). Ağırlıklandırma işlemi için literatürdeki diğer yöntemlere kıyasla SWARA yönteminin daha fazla kullanılması, diğer yöntemlere göre daha basit olmasından kaynaklanmaktadır. Bu durum araştırmacıların zamanı daha verimli kullanmasını ve maliyetten 
tasarruf etmesini sağlamaktadır (Zolfani vd., 2013, s.92; Çakır, 2018, s.1912).

Yöntemde karar verici olarak belirlenen uzmanların görüş ve fikirleri esas alındığından daha öznel değerlendirmelerin gerektirdiği çalışmalarda bu yöntem kullanılabilmektedir. Böylece karar vericiler ağırlıklandırma işleminde önceliklerin belirlenmesinde daha etkili olabilmektedir (Dahooie vd., 2018, s.10-11; Çakır, 2018, s.1912). Ayıca SWARA yönteminde karar vericiler mevcut ekonomik ve çevresel koşullar bağlamında kendi önceliklerini belirleyebilmekte ve böylece diğer yöntemlere göre daha etkin bir rol oynamaktadır (Zolfani ve Saparauskas, 2013, s.140).

SWARA yönteminde alternatifleri değerlendirmek için kullanılan kriterler en önemliden en önemsize doğru siralanmakta olup uzmanların görüş ve fikirlerine göre önemsiz olan kriterler elenmektedir. Daha sonra, elenmeyen kriterlerin önem ağırlıkları hesaplanırken tüm uzmanların kendisine göre oluşturduğu kriter siralaması esas alınmaktadır (Yurdoğlu ve Kundakcı, 2017, s.258; Kersuliene vd., 2010, s.247-250). Her bir uzman, kriter sıralamasını oluştururken en önemli olduğunu düşündüğü kritere "1.00" değerini vermektedir. Siralamaya dahil edilen diğer kriterlerin ise birinci sırada olan en önemli kritere göre $0.05^{\prime}$ er puanlık aralıklarla ne kadar önemsiz oldukları tespit edilmektedir. Tüm kriterlerin değeri " 0 " ile " 1 " arasında ve beşin katları olacak şekilde belirlenmektedir. Örneğin, birinci kritere kıyasla ikinci kriterin \%5 daha az önemli olduğu düşünülüyorsa ikinci kritere 0,95 değeri verilmektedir (Ayyıldız ve Demirci, 2018, s.80; Kersuliene ve Turskis, 2011, s. 654-655; Yurdoğlu ve Kundakc1, 2017, s.258). Ayn1 şekilde üçüncü kriterin ikinci kriterden \%5 daha az önemli olduğu düşünülüyorsa üçüncü kritere de 0,90 değeri verilmektedir. Kullanılan bütün kriterler birinci kriterle kıyaslanıp ona göre değerlendirildiğinden tüm kriterler için göreceli bir önem ağırlığı belirlenmektedir (Kersuliene ve Turskis, 2011, s.654-655).

SWARA yöntemini oluşturan beş adım yardımıyla belirlenen kriterlere ilişkin ağırlık değerleri hesaplanabilmektedir (Stanujkic vd., 2015, s.55-56; Prasad, 2019, s.135-136; Kersuliene vd., 2010, s.247-250; Karabasevic vd., 2016; 54; Karabasevic vd., 2017, s.17; Balki vd., 2020, s. 5-6; Dahooie vd., 2018, s.10-11). 
1. Adım: Kriterlerin Önem Düzeyine Göre Stralanması: En önemli olduğu düşünülen kriter birinci sırada olacak şekilde bütün kriterler uzmanların görüşlerine göre sıralanmaktadır. Bu adımda karar vericiler kendilerince en önemli olan kriteri tespit edip bu kritere " 1.00 " değerini vermektedir. Tüm kriterlere " 0 " ile " 1 " arasında ve 0,05 ' in katları olacak şekilde değer verilmektedir. Kriter değerleri eşitlik (1) de gösterilmektedir;

$$
p_{j}^{k} ; j=1, \ldots, k=1, \ldots, l ; 0 \leq p_{j}^{k} \leq 1
$$

2. Adım: Kriterlerin Göreli Önem Değerlerinin Belirlenmesi: Bu adımda karar vericiler birinci sıradaki kriter dışında kalan kriterlerin her biri için göreli önem değerlerini belirlemektedir. Bu amaçla j kriteri bir önceki kriter olan j-1 ile karşılaştırılır ve $\mathrm{s}_{\mathrm{j}}$ (ortalama değerin karşılaştırma oranı) değeri elde edilir. $\mathrm{sj}_{\mathrm{j}}$ değerinin elde edilmesiyle $\mathrm{j}$. kriterin $(\mathrm{j}-1)$. kriterden ne kadar önemli olduğu belirlenmektedir. Böylece art arda gelen tüm kriterler karşılaştırılıp ağırlık değerleri hesaplanır ve yüzdesel olarak önem düzeyleri tespit edilir.

3. Adım: $k_{j}$ Katsayısının Hesaplanması: Belirlenen tüm kriterler için $\mathrm{k}_{j}$ katsayısı eşitlik 2'den faydalanarak hesaplanmaktadır. $k_{j}$ katsayısı birinci kriter için 1 iken, oluşturulan sıralamada j. kriterden sonra gelen kriterlerin $\mathrm{k}_{\mathrm{j}}$ katsayı değeri bir önceki adımda hesaplanan $\mathrm{sj}_{\mathrm{j}}$ değeri (ortalama değerin karşılaştırma oranı) eklenerek bulunmaktadır.

$$
k_{j}=\left\{\begin{array}{cc}
1 & j=1 \\
s_{j}+1 & j>1
\end{array}\right.
$$

4. Adım: $q_{j}$ Değerinin Belirlenmesi: Belirlenen tüm kriterler için düzeltilmiş ağırlık değerleri qj eşitlik (3) yardımıyla hesaplanmaktadır.

$$
q_{j}=\left\{\begin{array}{cc}
1 & j=1 \\
\frac{q_{j-1}}{k_{j}} & j>1
\end{array}\right.
$$

5. Adım: Kriterlerin Nihai Ağırlık Değerlerinin Belirlenmesi: Son aşamada tüm kriterlerin nihai ağırlıkları aşağıda yer alan eşitlik (4) de gösterildiği gibi, j. kriterin düzeltilmiş ağırlık değerinin tüm kriterlerin 
düzeltilmiş ağırlık değerleri toplamına oranlanmasıyla hesaplanmaktadır. $\mathrm{w}_{\mathrm{j}}, \mathrm{j}$ kriterinin göreli ağırlı̆̆ını ifade etmektedir.

$$
w_{j}=\left\{\frac{q_{j}}{\sum_{k=1}^{n} q_{k}}\right.
$$

\section{ARAS Yöntemi}

ARAS (Additive Ratio Assessment) yöntemi ilk olarak Zavadskas ve Turksis (2010) tarafından farklı çok kriterli karar verme problemlerinin çözümünde ve analizinde kullanılmıştır. ARAS yöntemi fayda teorisine dayandığ 1 için belirlenen alternatifler fayda fonksiyonu değerleri dikkate alınarak sıralanmaktadır (Shariati vd., 2014, s.411; Pelitli vd., 2018). Bu doğrultuda ARAS yöntemini literatürdeki diğer çok kriterli karar verme yöntemlerinden farklılaşmaktadır (Bakır ve Atalık, 2018, s.623-624; Yıldırım, 2015, s.289).

Çok kriterli karar verme yöntemlerinde kullanılan klasik yaklaşım, sübjektif tasnif olarak da bilinen sıralamaya odaklanmaktır. Bu bağlamda literatürde yer alan birçok çok kriterli karar verme yöntemi ideal pozitif ve negatif çözüme olan göreli uzaklıkları temel almakta ve elde edilen çözümlere ait fayda fonksiyonu değerlerini ideal pozitif çözümün fayda fonksiyon değeri ile kıyaslamaktadır (Yıldırım, 2015, s.289; Koç ve Uysal, 2017, s.179). Fakat ARAS yönteminde alternatiflerin performansı belirlenirken her biri için optimal fayda sağlayan alternatife göre karşılaştırma oranları hesaplanmaktadır. Yani, ARAS yönteminde alternatiflere ait hesaplanan performans değerlerinin optimum fayda sağlayan alternatife göre oransal olarak benzerlikleri tespit edilmektedir (Pelitli vd., 2018; Ercan ve Kundakc1, 2017, s.90).

Aşağıda ARAS yöntemini oluşturan adımlar gösterilmiştir (Zavadskas ve Turskis, 2010, s.163-164; Karabasevic vd., 2018, s.726-727; Pelitli vd., 2018; Ercan ve Kundakc1, 2017, s.90-91; Arslan, 2017, s.276279).

1. Adım: Karar Matrisinin Oluşturulması: m alternatif, n kriter sayısı olmak üzere $X$ karar matrisi oluşturulmaktadır. 


$$
\begin{gathered}
\mathrm{X}=\left[\begin{array}{cccc}
x_{01} & x_{0 j} & \ldots & x_{0 n} \\
x_{i 1} & x_{i j} & \ldots & x_{i n} \\
\ldots & \ldots & \ldots & \ldots \\
x_{m 1} & x_{m j} & \ldots & x_{m n}
\end{array}\right] \\
i=0,1, \ldots, m \quad j=1,2, \ldots, n
\end{gathered}
$$

$X$ karar matrisinde $x_{i j}$ elemanı, $i$. alternatifin $j$. kriterdeki performans değerini ifade ederken, $\mathrm{x}_{0 \mathrm{j}}$ eleman $j$. kriterin optimal değerini ifade etmektedir. Karar problemin çeşitliliğine bağlı olarak kriterlerin optimal değerleri belirsiz ise aşağıdaki eşitlikler (6) ve (7) kullanılarak bu değerler belirlenmektedir.

Fayda Yönlü Kriterler İçin: $x_{0 j}=\max _{i} x_{i j}$

Maliyet Yönlü Kriterler İçin: $x_{0 j}=\min _{i} x_{i j}$

2. Adım: Normalize Karar Matrisinin Oluşturulması: Bu adımda X karar matrisi normalize edilmektedir. Çünkü kriterlerin birbirleriyle karşılaştırılmasını kolaylaştırmak için hepsinin ortak bir ölçek ya da birime dönüşümü yapılmalıdır. Farklı ölçek ve birimlerdeki kriterler ile işlem yapmak zordur. Bu bağlamda $\mathrm{X}$ karar matrisinin normalizasyonu ile birlikte farklı ölçek ve birimlerdeki veriler işlem yapılabilir duruma gelmektedir. $\bar{x}_{i j}$ elemanlarından oluşan normalize edilmiş $\bar{X}$ karar matrisinin elemanları işlem yapılan kriterin fayda (kriter performans değerinin yüksek olması) veya maliyet (kriter performans değerinin düşük olması) durumuna göre farklı değerlendirilmektedir.

Kriterler fayda durumunda olduğunda normalize edilmiş değerler eşitlik (8) yardımıyla belirlenebilmektedir.

$$
\text { Fayda Yönlü Kriterler İçin: } \bar{x}_{i j}=\frac{x_{i j}}{\sum_{i=0}^{m} x_{i j}}
$$

Kriterler maliyet durumda olduğunda normalize edilmiş değerleri belirlemek için 2 aşamalı bir işlem gerekmektedir. Birinci aşamada karar matrisindeki değerler eşitlik (9) ile fayda durumuna dönüştürülür ve daha sonra eşitlik (10) ile normalize değerler belirlenebilir.

$$
\begin{aligned}
& \text { Maliyet Yönlü Kriterler İçin: }=x_{i j}^{*}=\frac{1}{x_{i j}} \\
& \bar{x}_{i j}=\frac{x_{i j}^{*}}{\sum_{i=0}^{m} x_{i j}^{*}}
\end{aligned}
$$


$\mathrm{Bu}$ işlemler uygulanıp normalize değerler belirlendikten sonra normalize edilmiş $\bar{X}$ karar matrisi oluşturulur. Normalize matris eşitlik (11) de gösterilmiştir.

$$
\begin{aligned}
\overline{\mathrm{X}}= & {\left[\begin{array}{cccc}
\bar{x}_{01} & \bar{x}_{0 j} & \ldots & \bar{x}_{0 n} \\
\bar{x}_{i 1} & \bar{x}_{i j} & \ldots & \bar{x}_{i n} \\
\ldots & \ldots & \ldots & \ldots \\
\bar{x}_{m 1} & \bar{x}_{m j} & \ldots & \bar{x}_{m n}
\end{array}\right] } \\
& i=0,1, \ldots, m \quad j=1,2, \ldots, n
\end{aligned}
$$

3. Adım: Normalize Karar Matrisinin A ğırlıklandırılması: X karar matrisinin normalizasyonu sonucunda oluşturulan $\overline{\mathrm{X}}$ normalize karar matrisi, wj kriter ağırlıkları yardımıyla $\widehat{X}$ ağırlıklı normalize karar matrisine dönüştürülür. Belirlenen $w_{j}$ kriterlerinin $0<w j<1$ koşulunu sağlaması gerekmektedir. Bununla birlikte kriterlerin ağırlık toplamları da eşitlik (12) de gösterildiği gibi sınırlandırılmaktadır.

$$
\sum_{j=1}^{n} w_{j}=1
$$

Normalize edilmiş karar matrisinin elemanları kriter ağırlıklarıyla çarpılarak $\hat{x}_{i j}$ ağırlıklı normalize edilmiş karar matrisinin elemanları belirlenir (Eşitlik 13).

$$
\hat{x}_{i j}=\bar{x}_{i j} \cdot w_{i j}
$$

Belirlenen ağırlıklı normalize edilmiş karar matrisinin elamanları $\left(\hat{x}_{i j}\right.$ değerleri) eşitlik (14) de gösterilen matris formatında yazılır ve böylece $\widehat{X}$ ağırlıklı normalize edilmiş karar matrisi elde edilir.

$$
\begin{aligned}
\widehat{\mathrm{X}}= & {\left[\begin{array}{cccc}
\hat{x}_{01} & \hat{x}_{0 j} & \ldots & \hat{x}_{0 n} \\
\hat{x}_{i 1} & \hat{x}_{i j} & \ldots & \hat{x}_{i n} \\
\ldots & \ldots & \ldots & \ldots \\
\hat{x}_{m 1} & \hat{x}_{m j} & \ldots & \hat{x}_{m n}
\end{array}\right] } \\
& i=0,1, \ldots, m \quad j=1,2, \ldots, n
\end{aligned}
$$

4. Adım: Alternatiflerin Optimallik Fonksiyon Değerlerinin ( $\left.S_{i}\right)$ Hesaplanmasi: ARAS yöntemindeki dördüncü ve son adımda tüm alternatiflerin optimal değerleri hesaplanmakta ve alternatifler tek tek değerlendirilmektedir. Alternatiflerin optimal değerleri eşitlik (15) yardımıla belirlenmektedir.

$$
S_{i}=\sum_{j=1}^{n} x_{i j} ; i=0,1, \ldots, m
$$


Eşitlikteki $S_{i}$ değeri $i$. alternatifin optimum değerini ifade etmektedir. $S_{i}$ değeri büyüdükçe alternatife ait performansin daha iyi olduğu anlaşılmaktadır. Bu işlemden sonra tüm alternatiflerin $S_{i}$ değerleri $S_{0}$ optimal değerine bölünür ve böylece $K_{i}$ fayda değerleri belirlenir. $K_{i}$ değerlerinin belirlenmesi eşitlik (16) da gösterilmektedir.

$$
K_{i}=\frac{s_{i}}{s_{0}} ; i=0,1, \ldots, m
$$

Son olarak belirlenen $K_{i}$ değerleri alternatiflere ait fayda fonksiyonlarının değerlendirilmesinde kullanılmaktadır. Ayrıca $K_{i}$ değerlerinin büyükten küçüğe sıralanmasıyla en iyi alternatiften en kötü olan alternatife doğru sıralama elde edilmektedir. Böylece karar vericiler alternatiflerin hangisinin daha faydalı hangisinin daha maliyetli olduğunu kolayca tespit edebilmektedir.

\section{Türkiye'deki Ticari Bankalara Ait Web Sitelerinin Performans Analizi}

Bu çalışmanın amacı Türkiye'deki 15 ticari bankaya ait web sitelerin performansını analiz ederek sıralama yapmaktır. Web sitelerinin performans kriterlerine göre sıralanması SWARA ve ARAS yöntemleri kullanılarak yapılmıştır. Analizlerde ele alınacak kriterlerin belirlenmesinde literatürde bulunan ve web siteleri çeşitli özellikleri doğrultusunda inceleyen çalışmalardan faydalanılmıştır. Waisberg ve Kaushik (2009), web sitesi performansı için siteden hemen ayrılma oranı, ziyaretçi sayısı, web sitesinde geçirilen ortalama süre ve görüntülenen sayfa sayısı kriterlerinin önem arz ettiğini belirtmiştir. Booth ve Jansen (2010), web sitesi hızı, sayfaların açılma süresi, ziyaretçi sayısı, ortalama geçirilen süre ve siteden hemen ayrilma oranı kriterlerinin anahtar performans belirleyiciler olduğunu vurgulamıştır. Carmona vd. (2012), kaliteli ve performansı iyi olan bir web sitesi için ziyaretçi sayısı, web sitesinde ziyaretçilerin geçirdikleri ortalama süre ve ziyaret başına görüntülenen sayfa sayısının önemli olduğunu vurgulamıştır. Pakkala vd. (2012) web sitesi performans göstergelerinden ziyaretçi sayısı, web sitesinde geçirilen ortalama süre, ziyaret başına görüntülenen sayfa sayıs1 ve insanların siteden hemen ayrılma oranının önemini vurgulamıştır. Zhu vd. (2013), web sitesi performansında en etkili kriterlerden birinin web sitesi hızı ve web sitesinin açılma süresi 
olduğunu vurgulamıştır. Nagy (2013), web sitesi hızının ve açılma süresinin performans için önemini belirtmiş ve kaliteli web sitesi için web sitesi hızının artırılması gerektiğini vurgulamıştır. Elisa (2017), kaliteli ve performansı iyi olan bir web sitenin web sitesi hızı, sayfa açılma süresi ve sayfa boyutu kriterlerinin iyi olması gerektiğini belirtmiştir. Sulova (2019), ziyaretçi sayısı, web sitesinde geçirilen ortalama süre, ziyaret başına görüntülenen sayfa sayısı ve insanların siteden hemen ayrilma oranının en önemli web sitesi performans göstergelerinden olduğunu belirtmiştir. Ayrıca literatürdeki çalışmalarda önemi vurgulanan kriterler web sitelerinin dünyadaki ve Türkiye'deki web sitelere kıyasla kaçıncı sırada olduğunu da etkilemektedir.

İncelenen çalışmalar doğrultusunda bu çalışmada sıralama kriterleri olarak; web sitesi performansı (\%), web sitesinin hızı endeksi (saniye), web sitesinin tamamen açılma süresi (saniye), web sitesi sayfa boyutu $(\mathrm{mb})$, ziyaretçilerin web sitesinden hemen ayrılma oranı $(\%)$, toplam ziyaretçi sayısı, web sitesinin dünya sıralaması, web sitesinin Türkiye sıralaması, web sitesinde geçirilen ortalama süre (dakika) ve ziyaret başına görüntülenen ortalama sayfa sayısı kriterleri kullanılmıştır. Web sitesi performansı (\%), web sitesinin hızı endeksi (saniye), web sitesinin tamamen açlma süresi (saniye) ve web sitesi sayfa boyutu (mb) kriterlerine ilişkin veriler Gtmetrix.com'dan elde edilirken, ziyaretçilerin web sitesinden hemen ayrılma oranı (\%), toplam ziyaretçi sayısı, web sitesinin dünya sıralaması, web sitesinin Türkiye sıralaması, web sitesinde geçirilen ortalama süre (dakika) ve ziyaret başına görüntülenen ortalama sayfa sayısı kriterlerine ilişkin veriler Similarweb.com'dan elde edilmiştir. Bu kapsamda Tablo 1'de analiz edilen 15 ticari bankanın web sitelerine ilişkin performans kriterleri ve değerleri yer almaktadır. Veri seti Şubat 2021'de oluşturulmuş olup web sitelerinin Ocak 2021'deki performanslarını göstermektedir. 
Tablo 1. Web Sitesi Değerlendirme Kriterleri ve Değerler

\begin{tabular}{|c|c|c|c|c|c|c|c|c|c|c|}
\hline BANKALAR & 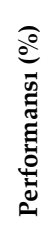 & 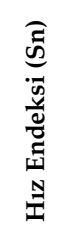 & 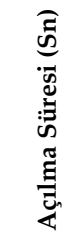 & 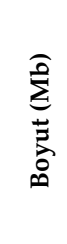 & 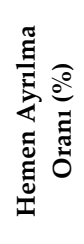 & 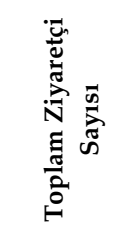 & 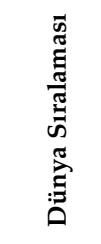 & 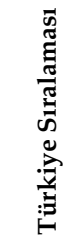 & 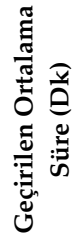 & 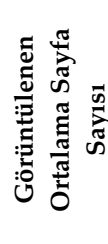 \\
\hline Akbank & 6 & 7,20 & 13,60 & 2,24 & 58,7 & 4.400 .000 & 14.625 & 30 & 2,31 & 2,92 \\
\hline Deniz Bank & 22 & 4,00 & 19,20 & 2,38 & 40,02 & 2.490 .000 & 23.191 & 45 & 4,59 & 3,87 \\
\hline Fiba Bank & 66 & 4,20 & 4,70 & 1,60 & 55,56 & 535.390 & 106.186 & 2.191 & 2,48 & 2,53 \\
\hline Garanti BBVA & 16 & 4,60 & 10,00 & 3,43 & 27 & 6.350 .000 & 6.594 & 146 & 6,15 & 7,87 \\
\hline Halkbank & 18 & 4,80 & 8,50 & 2,65 & 28,06 & 4.300 .000 & 12.355 & 260 & 5,53 & 4,87 \\
\hline HSBC & 87 & 1,00 & 1,80 & 5,61 & 55,79 & 427.530 & 105.958 & 2.496 & 3,41 & 3,66 \\
\hline ING Bank & 9 & 6,80 & 10,60 & 2,22 & 54,65 & 1.430 .000 & 36.934 & 720 & 2,38 & 3,91 \\
\hline İş Bankası & 39 & 4,90 & 9,50 & 1,40 & 31,59 & 7.430 .000 & 6.878 & 155 & 5,08 & 4,89 \\
\hline OdeaBank & 14 & 7,90 & 8,10 & 3,27 & 37,42 & 204.780 & 202.092 & 4.469 & 6,32 & 3,78 \\
\hline QNB Finans Bank & 24 & 6,20 & 12,00 & 0,97 & 52,63 & 2.620 .000 & 19.817 & 397 & 3,46 & 4,44 \\
\hline Şeker Bank & 48 & 3,70 & 7,40 & 3,81 & 33,70 & 327.030 & 122.008 & 2.529 & 4,24 & 5,07 \\
\hline TEB & 32 & 9,80 & 11,70 & 1,51 & 35,09 & 1.620 .000 & 25.428 & 501 & 5,38 & 7,15 \\
\hline Vakıfbank & 47 & 4,50 & 6,70 & 2,09 & 38,15 & 4.950 .000 & 9.809 & 212 & 4,30 & 6,04 \\
\hline Yapı ve Kredi Bankası & 44 & 3,50 & 10,30 & 1,39 & 38,64 & 5.690 .000 & 11.503 & 246 & 3,20 & 3,05 \\
\hline Ziraat Bankası & 21 & 5,80 & 12,20 & 1,96 & 40,28 & 10.590 .000 & 3.644 & 85 & 3,48 & 8,38 \\
\hline
\end{tabular}

Tablo 1'de yer alan kriterlerden; hız endeksi, açılma süresi, boyut, hemen ayrılma oranı, dünya sıralaması ve Türkiye sıralaması kriterleri minimizasyon yönlü, diğer kriterler maksimizasyon yönlü kriterleridir. Kriter değerlerinin belirlenmesinden sonra ilk aşamada SWARA yöntemiyle kriter ağırlıkları belirlenmiştir. Bu amaçla web tasarımı üzerine çalışan bir uzman görüşü doğrultusunda belirlenen kriterlere ilişkin göreli önem puanları ve hesaplanan kriter ağırlık değerleri Tablo 2 ' de verilmiştir.

Kriter ağırlıklarının belirlenmesinden sonra Tablo 1'de yer alan verilere göre ARAS yöntemiyle ticari bankaların web siteleri sıralanmıştır. Bu işlem için ilk olarak kriterler için optimal değerler belirlenmiştir. Optimal değerler olarak maksimize edilmesi istenen kriterler için maksimum değerler, minimize edilmesi istenen kriterler için minimum değerler alınmıştır. 
Tablo 2. SWARA Yöntemi ile Hesaplanan Kriter A ̆̆ırlık Değerleri

\begin{tabular}{lcccc}
\hline KRITERLER & $\boldsymbol{s}_{\boldsymbol{j}}$ & $\boldsymbol{k}_{\boldsymbol{j}}$ & $\boldsymbol{q}_{\boldsymbol{j}}$ & $\begin{array}{c}\text { Kriter } \\
\text { A.̆ırlığ }\end{array}$ \\
\hline Performans (\%) & 1 & 1 & 1 & 0,337 \\
Açılma Süresi (Sn) & 0,6 & 1,6 & 0,625 & 0,211 \\
Hız Endeksi (Sn) & 0,55 & 1,55 & 0,403226 & 0,136 \\
Boyut (Mb) & 0,5 & 1,5 & 0,268817 & 0,09 \\
Görüntülenen Ortalama Sayfa Sayısı & 0,4 & 1,4 & 0,192012 & 0,065 \\
Toplam Ziyaretçi Sayısı & 0,35 & 1,35 & 0,142231 & 0,048 \\
Hemen Ayrılma Oranı (\%) & 0,3 & 1,3 & 0,109409 & 0,037 \\
Geçirilen Ortalama Süre (Dk) & 0,25 & 1,25 & 0,087527 & 0,029 \\
Dünya Siralaması & 0,2 & 1,2 & 0,072939 & 0,025 \\
Türkiye Siralaması & 0,1 & 1,1 & 0,066308 & 0,022 \\
\hline
\end{tabular}

Tablo 3'te bankaların web sitelerinin belirlenen kriterlere göre sıralama değerleri verilmiştir.

Tablo 3. Ticari Banka Web Sitelerinin Performanslarnın ARAS Yöntemi ile Stralama Sonuçları

\begin{tabular}{lcc}
\hline Bankalar & Fayda Değerleri & Siralama \\
\hline Akbank & 0,194 & 15 \\
Deniz Bank & 0,237 & 12 \\
Fiba Bank & 0,342 & 2 \\
Garanti BBVA & 0,283 & 8 \\
Halkbank & 0,274 & 10 \\
HSBC & 0,770 & 1 \\
ING Bank & 0,209 & 14 \\
İş Bankası & 0,306 & 5 \\
OdeaBank & 0,304 & 6 \\
QNB Finans Bank & 0,266 & 11 \\
Şeker Bank & 0,321 & 3 \\
Türkiye Ekonomi Bankası & 0,232 & 13 \\
Vakıfbank & 0,294 & 7 \\
Yapı ve Kredi Bankası & 0,310 & 4 \\
Ziraat Bankası & 0,280 & 9 \\
\hline
\end{tabular}

\section{Tartışma ve Sonuç}

Günümüzde teknolojik gelişmeler ve küreselleşmenin etkisiyle dünya genelinde internet kullanım oranı ve internet kullanıcı sayısı artmaktadır Özellikle covid-19 pandemisiyle birlikte ticari ve sosyal yaşamda önemli gelişmeler yaşanmıştır. Bu durum küresel açıdan ciddi bir probleme 
neden olmuş ve birçok ekonomik aktivite değişime maruz kalmıştır (Nakhate and Jain, 2020). İnsanlar hastalığa yakalanmaktan korktuğu için fiziksel temastan kaçınmış ve bu nedenle birçok faaliyet internet ortamına taşınmıştır. Yapılan araştırmalara göre covid-19 pandemi döneminde insanların \%52'si birçok işlemi fiziksel olarak gitmek yerine internet ortamında gerçekleştirmektedir (Bhatti vd., 2020, s.1450; Tran, 2020, ss.1-2). Ayrica covid-19 ile mücadele kapsamında bu dönemde salgının yıkıcı etkisini azaltmak amacıyla devletler tarafından birçok sosyal, ekonomik ve finansal tedbir alınmıştır. Evde kal çağrısı, sokağa çıkma kısıtlamaları, sosyal mesafe kuralı ve maske takma zorunluluğu gibi uygulamalar insanların interneti daha fazla kullanmasına sebep olmuştur. Özellikle internet üzerinden alışveriş (e-ticaret) (Pantelimon vd., 2020; Tran, 2020) ve internet bankacilığ1 kullanımı ciddi bir artış göstermiştir (Beybur ve Çetinkaya, 2020, s.149-150). İnternet bankacılığ1 kullanımının artması da bankalara ait web sitelerinin çeşitli özellikleri ve yönleri açısından önemini artırmıştır.

$\mathrm{Bu}$ nedenle çalışmada Türkiye'deki 15 ticari banka web sitesinin performansları analiz edilerek bir sıralama yapılmıştır. Banka web sitelerinin performans kriterlerine göre siralanmasında SWARA ve ARAS yöntemleri kullanılmıştır.

Ticari bankaların web sitelerini sıralama kriterleri literatürde daha önce web siteleri ile ilgili yapılmış olan çalışmalarda kullanılan kriterlerdir. Kriterlerin tespit edilmesinden sonra ilk olarak SWARA yöntemi ile kriter ağırlıkları belirlenmiştir. Bu amaçla web yazılımı üzerine çalışan bir uzmandan görüş alınmış ve belirlenen kriterlere ilişkin göreli önem puanları hesaplanmıştır. SWARA yöntemi sonucuna göre sırasıyla web sitesi performansı $(0,337)$, sayfa açılma süresi $(0,211)$ ve hız endeksi $(0,136)$ kriterlerinin en yüksek kriter ağırlığına, web sitesinde geçirilen ortalama süre $(0,029)$, dünya sıralaması $(0,025)$ ve Türkiye sıralaması $(0,022)$ kriterlerinin ise en düşük kriter ağırlığına sahip olduğu görülmüştür.

Tüm bankalar ve her bir kriter için kriter ağırlıkları hesaplandıktan sonra ARAS yöntemi ile 15 ticari bankanın web sitesi performanslarına göre siralanmiştır. ARAS yöntemi sonucunda hesaplanan fayda değerlerine göre sirasıyla HSBC $(0,770)$, Fiba Bank $(0,347)$ ve Şeker Bank $(0,321)$ en iyi performans gösteren web sitelerine sahiptir ve yapılan 
sıralamada ilk üç sırada yer almaktadır. Türkiye Ekonomi Bankası $(0,232)$, ING Bank $(0,209)$ ve Akbank $(0,194)$ ise en kötü performans gösteren web sitelerine sahip olup yapılan sıralamada son üç sırada yer almaktadır.

Çalışmada belirlenen kriterlerin hangisinin web siteleri için ne derecede önemli ve etkili olduğu ortaya konulmuştur. Web sitesi performans oranı, web sitesindeki sayfaların açılma süresi ve web sitesinin hız indeksi iyi olan bankaların yapılan sıralamada üstlerde olduğu görülmektedir. Ayrıca bu çalışma internet bankacılığının önem kazandığı günümüzde banka web sitelerinin hangi özellikler yönünden gelişmesi ve performansı iyi bir web sitesi için hangi kriterlere önem verilip hangilerine yatırım yapılması gerektiği konusunda yol göstermektedir. Bu bağlamda çalışma internet bankacilığında rekabet avantajı elde etmek isteyen ve web sitelerini geliştirmek isteyen bankalara 1şık tutmaktadır.

Bununla birlikte literatür incelendiğinde banka web siteleri ile ilgili çalışmalarda daha önce SWARA ve ARAS yöntemlerinin kullanılmadığ görülmektedir. Önceki çalışmalarda AHP, TOPSIS, VIKOR, COMET, COPRAS-G gibi daha farklı çok kriterli karar verme yöntemleri kullanılmıştır. Çalışma bu yönüyle farklılaşmaktadır.

Gelecek çalışmalarda farklı performans kriterleri belirlenerek ve farklı yöntemler kullanılarak analizlerin yinelenmesi literatüre katkı sağlayacaktır. Ayrıca gelecek çalışmalarda bu çalışmada kullanılmayan bankaların web siteleri analiz edilebilir. Bununla birlikte verilerin belirli bir tarihte Gtmetrix.com ve Similarweb.com'dan elde edilmesi önemli bir kisittır.

Farklı aylarda elde edilen verilerle yapılan analizlerde farklı performans kriterleri ön plana çıkıp farklı bankalar sıralamada üst sıralarda yer alabilir. Bunun da sonuçları farklılaştırıp literatüre katkı sağlayacağı düşünülmektedir. Bu bağlamda gelecek çalışmalarda farklı ülkelerdeki bankaların karşılaştırmalı analizi de literatüre önemli katkılar sağlayacaktır. Ayrıca gelecek çalışmalarda pandemi öncesi döneme ait veriler ile yapılan analizlerle pandemi dönemindeki değişim ve farklar tespit edilebilir. 


\title{
EXTENDED ABSTRACT
}

\section{Ranking of Web Sites Performance of Commercial Banks in Turkey by SWARA and ARAS Method}

\author{
* \\ Muhammed Maruf - Kadir Özdemir \\ Kırşehir Ahi Evran University- Şırnak University
}

With the effect of technological advancements and globalization, internet usage is increasing day by day in worldwide. For this reason, the strategic importance of digitalization has increased in many sectors and digital transformation has accelerated. Accordingly, It can be said that, the banking sector is more ready for digital transformation than other sectors (Beybur ve Çetinkaya, 2020, s.148). With the digital transformation in the banking sector, many banks have commenced to offer lots of services on their websites. Thus, the significance of banks websites has increased and have become an integral part of business process. Especially in today's world where the usage and significance of internet banking is increasing, websites are more significant for banks to achieve their mission and vision and gain competitive advantages (Özdemir ve Turna, 2020, s.39).

When the studies about websites of banks is examined in the literature, it is seen that the general tendencies are the content analysis of websites and to comprehend and discuss the impact of some determined criteria on the usage of websites. In this context, there are not many studies which are examining the websites performance of banks with certain criteria. For instance, Ecer (2014) analyzed the website quality of 17 banks in Turkey with using AHP and COPRAS-G methods. The criteria used in the study are information quality, service quality, system quality, accessibility, reliability etc. Akgül (2018) analyzed the websites of 32 banks in Turkey with the criteria such as accessibility, usability, security, website performance, opening time of website and page size. Chmielarz and Zborowski (2018) analyzed the website quality and performance of 21 banks in Poland with using the TOPSIS method.

Multi-criteria decision-making methods (MCDM) are used to rank decision alternatives. In the literature, there are many multi-criteria 
decision methods applied for the purpose of weighting the decision criteria and ranking the alternatives. SWARA method which are used in solving many different problems is one of the most significant and widely used criteria weighting method. The SWARA method is based on the opinions and ideas of the decision makers. Therefore, in this method, decision makers can determine their own priorities in the context of economic and environmental conditions and thus, they can play a more active role compared with the other methods (Zolfani ve Saparauskas, 2013, s.140; Dahooie vd., 2018, s.10-11). In recent years, one of the most widely used alternative ranking methods in the literature is the ARAS method. In the ARAS method, the utility function values of the determined alternatives are considered, and the alternatives are ranked according to their utility value (Pelitli vd., 2018; Shariati vd., 2014, s.411; Ercan ve Kundakcl, 2017, s.90).

The main objective of this study to analysis and rank of 15 commercial banks' websites in Turkey according to website performance criteria Accordingly, the ranking criteria were determined based on studies in the literature. In this context, based on the literature, the criteria used in the study are website performance (\%), website speed index (seconds), website opening time (seconds) and website page size $(\mathrm{mb})$, rate of visitors leaving the website immediately (\%), total number of visitors, the website's world ranking, the website's Turkey ranking, the average time spent on the website (minutes) and the average number of pages viewed per visit. SWARA (Step-Wise Weight Assessment Ratio Analysis) and ARAS (Additive Ratio Assessment) methods were used to rank the websites.

In the study, firstly, criterion weights were determined by SWARA method. For this purpose, the opinion of an expert who are working on web software was taken and the relative importance scores of the determined criteria were calculated. According to the results of the SWARA method, website performance (0.337), page opening time $(0.211)$ and website speed index (0.136) have the highest criterion weight, while the average time spent on the website (0.029), website's world ranking $(0.025)$ and website's Turkey ranking (0.022) have the lowest criterion weight. 
After calculating the criteria weights for all banks and for each criterion, the websites of 15 commercial banks in Turkey were ranked according to their performance using the ARAS method. Benefit values calculated as a result of the ARAS method, HSBC (0.770), Fiba Bank (0.347) and Şeker Bank (0.321) have the best performing websites and are in the top three in the ranking. Turkish Economy Bank (0.232), ING Bank (0.209) and Akbank (0.194) have the worst performing websites and are in the last three in the ranking.

Consequently, it has been determined that which of the criteria is important and effective for bank's websites. In addition, it is revealed that the banks which have adequate website performance, page opening time and the speed index are at the top of the rankings. Also, this study provides guidance on what features bank's websites should develop and which criteria is significant to good websites performance. Accordance with this guidance banks invest in prominent features and performance criteria. In this context, this study is important for banks that desire to improve their websites and gain a competitive advantage in internet banking. However, when the literature is examined, it is seen that SWARA, and ARAS methods have not been used previous studies regarding bank websites. In previous studies, different multi-criteria decision-making methods such as AHP, TOPSIS, VIKOR, COMET, COPRAS-G were used. Therefore, with all these aspects, this study differs and contribute to the literature and business environment.

\section{Kaynakça / References}

Akgül, Y. (2018). Banking websites in Turkey: An accessibility, usability and security evaluation. Journal of Business Research - Turk, 10(1), 782-796.

Arslan, H. M. (2017). AHP-ARAS hibrit yöntemi ile lojistik işletmelerinin en uygun araç seçimi. Alphanumeric Journal, 5(2), 271-282.

Ayyıldız, E. ve Demirci, E. (2018). Türkiye'de yer alan şehirlerin yaşam kalitelerinin SWARA entegreli TOPSIS yöntemi ile belirlenmesi. Pamukkale Üniversitesi Sosyal Bilimler Enstitüsü Dergisi, 30, 67-87.

Bakır, M. ve Atalık, Ö. (2018). Entropi ve ARAS yöntemleriyle havayolu işletmelerinde hizmet kalitesinin değerlendirilmesi. Journal of Business Research - Turk, 10(1), 617-638. 
Balki, M. K., Erdoğan, S., Aydın, S. ve Sayin, C. (2020). The optimization of engine operating parameters via SWARA and ARAS hybrid method in a small SI engine using alternative fuels. Journal of Cleaner Production, 258, 1-12.

Beybur, M. ve Çetinkaya, M. (2020). Covid-19 pademisinin Türkiye'de dijital bankacılık ürün ve hizmetlerin kullanımı üzerindeki etkisi. International Journal of Western Black Sea Socialand Humanities Sciences, $4(2), 148-163$.

Bhatti, A., Akram, H., Basit, H. M., Khan, A. U., Naqvi, S. M. Raza, ve Bilal, M. (2020). E-commerce trends during COVID-19 Pandemic. International Journal of Future Generation Communication and Networking, 13(2), 1449-1452.

Booth, D. and Jansen, B. J. (2010). A review of methodologies for analyzing websites. Web technologies: Concepts, methodologies, tools, and applications, In B.J. Jansen, A. Spink \& I. Taksa (Eds.), Handbook of research on web log analysis. 145-166. Hershey, PA.: IGI.

Carmona, C. J., Ramírez-Gallego, S., Torres, F., Bernal, E., Del Jesus, M. J. and García, S. (2012). Web usage mining to improve the design of an e-commerce website: Or OliveSur.com. Expert Systems with Applications, 39(12), 11243-11249.

Chmielarz, W. and Zborowski, M. (2018a). Analysis of e-banking websites' quality with the application of the TOPsIs method - apPractical study. Procedia Computer Science, 126, 1964-1976.

Chmielarz, W. and Zborowski, M. (2018). On analysis of e-banking websites quality - Comet application. Procedia Computer Science, 126, 21372152.

Çakır, E. (2018). Bütünleşik SWARA ve EDAS yöntemï kullanarak fïtnes merkezlerïnin değerlendïrilmesï: Örnek bïr uygulama. Hitit Üniversitesi Sosyal Bilimler Enstitüsü Dergisi, 11(3), 1907-1923.

Dahooie, H., J., Beheshti Jazan Abadi, E., Vanaki, A. S. and Firoozfar, H. R. (2018). Competency-based IT personnel selection using a hybrid SWARA and ARAS-G methodology. Human Factors and Ergonomics In Manufacturing, 28(1), 5-16.

Dehsiri, H., J., S. and Aghaei, M. (2020). Identifying and prioritizing human resources risks through the combination of SWARA and gray ARAS. Journal of Human Resource Studies, 10(1), 53-78. 
Ecer, F. (2014). A hybrid banking websites quality evaluation model using AHP and COPRAS-G: A turkey case. Technological and Economic Development of Economy, 20(4), 758-782.

Elisa, N. (2017). Usability, accessibility and web security assessment of egovernment websites in Tanzania. International Journal of Computer Applications, 164(5), 42-48.

Ercan, E. ve Kundakc1, N. (2017). Bir tekstil işletmesi için desen programı seçiminde ARAS ve OCRA yöntemlerinin karşılaştırılması. Afyon Kocatepe Üniversitesi Sosyal Bilimler Dergisi, 1, 83-105.

GTmetrix (2020). How fast does your website load? Find out with GTmetrix. https://gtmetrix.com/. Erişim tarihi: 07.02.2021.

Gümüş, U. T., Öziç, H. C. ve Sezer, D. (2019). BİST' te inşaat ve bayındırlık sektöründe işlem gören işletmelerin SWARA ve ARAS yöntemleriyle finansal performanslarının değerlendirilmesi. OPUS Uluslararası Toplum Araştırmaları Dergisi, 10(17), 835-858.

Ighravwe, D. E. and Oke, S. A. (2019). A multi-criteria decision-making framework for selecting a suitable maintenance strategy for public buildings using sustainability criteria. Journal of Building Engineering, 24(March), 100753.

Karabasevic, D., Stanujkic, D. and Urosevic, S. (2015). The MCDM model for personnel selection based on SWARA and ARAS methods. Management - Journal for theory and practice of management, 20(77), 4352.

Karabasevic, D., Zavadskas, E. K., Turskis, Z. and Stanujkic, D. (2016). The framework for the selection of personnel based on the SWARA and ARAS methods under uncertainties. Informatica (Netherlands), 27(1), 49-65.

Karabasevic, D., Stanujkic, D., Urosevic, S., Popovic, G. and Maksimovic, M. (2017). An approach to criteria weights determination by integrating the DELPHI and the adapted SWARA methods. Management: Journal of Sustainable Business and Management Solutions in Emerging Economies, 22(3), 15-25.

Karabasevic, D., Maksimović, M., Stanujkić, D., Jocić, G. and Rajčević, D. (2018). Selection of software testing method by using ARAS method. Tehnika, 73(5), 724-729.

Kersuliene, V., Zavadskas, E. K. and Turskis, Z. (2010). Selection of rational dispute resolution method by applying new step-wise weight 
assessment ratio analysis (SWARA). Journal of Business Economics and Management, 11(2), 243-258.

Keršulienė, Violeta, and Zenonas Turskis. 2011. Integrated fuzzy multiple criteria decision making model for architect selection. Technological and Economic Development of Economy 17(4), 645-66.

Koc, N. ve Uysal, F. (2017). Reverse logistics and application of ARAS method. Pressacademia, Journal of Management, Marketing and Logistics $4(2), 178-185$.

Korucuk, S. (2019). ÇKKV yöntemleri ile imalat işletmelerinde TZY performans faktörlerinin önem derecelerinin belirlenmesi ve en ideal rekabet stratejisi seçimi: Ordu ili örneği. Dokuz Eylul Universitesi Iktisadi ve Idari Bilimler Dergisi, 33(2), 569-593.

Mostafaeipour, A., Dehshiri, S. J. H., Dehshiri, S. S. H. and Jahangiri, M. (2020a). Prioritization of potential locations for harnessing wind energy to produce hydrogen in Afghanistan. International Journal of Hydrogen Energy, 45(58), 33169-33184.

Mostafaeipour, A., Hosseini Dehshiri, S. J. and Hosseini Dehshiri, S. S. (2020b). Ranking locations for producing hydrogen using geothermal energy in Afghanistan. International Journal of Hydrogen Energy, 45(32), 15924-15940.

Nagy, Z. (2013). Improved speed on intelligent web sites. Recent Advances in Computer Science, 1(14), 215-220.

Nakhate, S. B. and Jain, N. (2020). The effect of coronavirus on e-commerce. Studies in Indian Place Names, 40(68), 516-518.

Oyefolahan, O., I., A. Sule, A., A. Adepoju, S. and Babakano, F. (2019). Keeping with the global trends: An evaluation of accessibility and usability of Nigerian banks websites. International Journal of Information Engineering and Electronic Business, 11(2), 44-53.

Özdemir, M. and Turna, G. B. (2020). Website performances of commercial banks in Turkey. Dumlupınar Üniversitesi Sosyal Bilimler Dergisi, 64, 38-52.

Pakkala, H., Presser, K. and Christensen, T. (2012). Using Google Analytics to measure visitor statistics: The case of food composition websites. International Journal of Information Management, 32(6), 504-512.

Pantelimon, F., Georgescu, T. and Posedaru, B. Ş. (2020). The impact of mobile e-commerce on GDP: A comparative analysis between 
Romania and Germany and how Covid-19 influences the ecommerce activity worldwide. Informatica Economică, 24(2), 27-41.

Pelitli, T., Karagöz, E., Özbek, D. ve Yaralıo, K. (2018). Karar verme yöntemleri ARAS ve TOPSIS ile besin tercihlerine yönelik web tabanl uygulama. 5th International Management Information Systems Conference, October 24.

Prasad, R. (2019). Selection of internal safety auditors in an Indian construction organization based on the SWARA and ARAS methods. Journal of Occupational Health and Epidemiology, 8(3), 134140.

Sarkar, A. ve Pal, A. (2018). Websites of Indian banks: A webometric study. Library Philosophy and Practice (e-journal). 1-18.

Shariati, S., Yazdani-Chamzini, A., Salsani, A. and Tamosaitiene, J. (2014). Proposing a new model for waste dump site selection: Case study of ayerma phosphate mine. Inzinerine Ekonomika-Engineering Economics, 25(4), 410-419.

Similarweb, (2020). Traffic overview. https://www.similarweb.com/. Erişim tarihi: 07.02.2021.

Stanujkic, D., Djordjevic, B., and Karabasevic, D. (2015). Selection of candidates in the process of recruitment and selection of personnel based on the SWARA and ARAS methods. Quaestus Multidisciplinary Research Journal, 7, 53-64.

Sulova, S. (2019). A system for E-commerce website evaluation. International Multidisciplinary Scientific GeoConference Surveying Geology and Mining Ecology Management, SGEM, 19(2.1), 25-32.

Thompson, M. F., Tuzovic, S. and Braun, C. (2019). Trustmarks: Strategies for exploiting their full potential in e-commerce. Business Horizons, 62(2), 237-247.

Tran, L. T. T. (2020). Managing the effectiveness of e-commerce platforms in a pandemic. Journal of Retailing and Consumer Services, 58, 102-287.

Vockic, M., Stojic, G. and Stevic, B. (2018). Integrated rough SWARA-ARAS model for selection of electric forklift. The $2 n d$ International Conference on Management, Engineering and Environment, 216-227.

Waisberg, D. and Kaushik, A. (2009). Web Analytics 2.0: Empowering customer centricity. The original Search Engine Marketing Journal, 2(1), $5-11$. 
Yıldırım, B. F. (2015). Çok krïterlï karar verme problemlerinde ARAS yöntemi. Kafkas Üniversitesi İktisadi ve İdari Bilimler Fakültesi Dergisi, 6(9), 285-296.

Yurdoğlu, H. ve Kundakcı, N. (2017). SWARA ve WASPAS yöntemlerï ile sunucu seçïmi. Balıkesir Üniversitesi Sosyal Bilimler Enstitüsü Dergisi, 20(38), 253-270.

Zavadskas, E. K. and Turskis, Z. (2010). A new additive ratio assessment (ARAS) method in multicriteria decision-making. Technological and Economic Development of Economy, 16(2), 159-172.

Zhu, J., Chan, D. S., Prabhu, M. S., Natarajan, P., Hu, H. and Bonomi, F. (2013). Improving web sites performance using edge servers in fog computing architecture. Proceedings - 2013 IEEE 7th International Symposium on Service-Oriented System Engineering, SOSE 2013, 320323.

Zolfani, H., S., Esfahani, M. H., Bitarafan, M., Zavadskas, E. K. and Arefi, S. L. (2013). Developing a new hybrid mcdm method for selection of the optimal alternative of mechanical longitudinal ventilation of tunnel pollutants during automobile accidents. Transport, 28(1), 8996.

Zolfani H., S. and Saparauskas, J. (2013). New application of SWARA method in prioritizing sustainability assessment indicators of energy system. Engineering Economics, 24(5), 408-414.

\section{Kaynakça Bilgisi / Citation Information}

Maruf, M. ve Özdemir, K. (2021). Türkiye'deki ticari bankalara ait web sitelerin performanslarının SWARA ve ARAS yöntemi ile sıralanması. OPUS-Uluslararası Toplum Araştırmaları Dergisi, 18(Yönetim ve Organizasyon Özel Sayıs1), 1514-1537. DOI: 10.26466/opus. 888184 . 